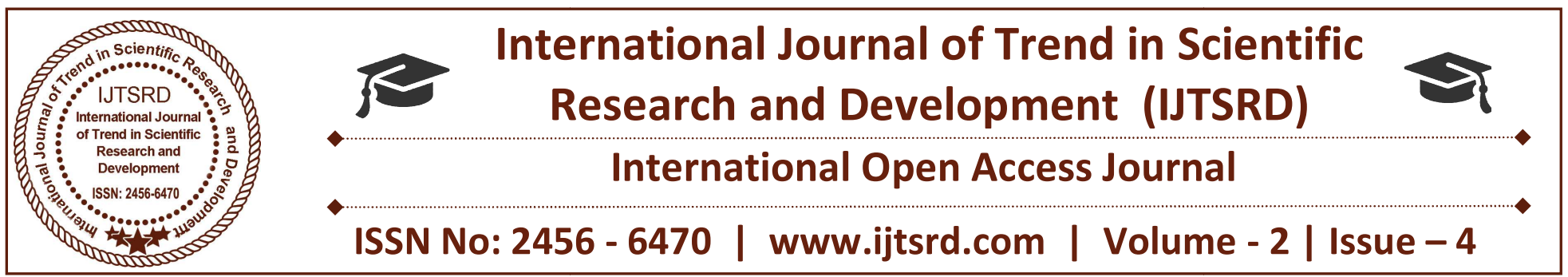

\title{
Railway Ticket Booking System with Restricted Wi-Fi Zone
}

\author{
Gayatri Shelar, Vikas Rathod, Prof. Shital Patil \\ Department of Computer Engineering, \\ SRTTC Engineering College, Pune, Maharashtra, India
}

\begin{abstract}
The main aim of the proposed system is to reform the current ticket booking process for Suburban Railway. With the help of this application travellers will be able to book the ticket through their mobile using the WIFI connectivity. It can also keep the track of most recent tickets purchases. This is an effort towards queue less ticket booking system and helps passengers utilize their time, which they waste awaiting in the queue. This system provides facility and flexibility to book the ticket using restricted WI-FI zones available on platforms. Provided Android application can be only accessed within the WI-FI zones only. After ticket booking, tickets will be downloaded directly on smart Phones. Users can directly carry the E-Ticket in the train.
\end{abstract}

Keywords: Suburban Railway; WI-FI connectivity; ETicket

\section{INTRODUCTION}

India a country with population of 1.34 billion people is the second most populous country in the world where suburban Railway plays a major role in public transport. Suburban trains are also referred as "Local Trains" or "Locals". About 30 million of people travel in Indian Railways daily and about 7.5 million travels on Mumbai locals daily. Today's era is an era of technology where world is getting more and more connected. Mobile technology is playing vital role nowadays as more number of users are active on mobile devices than desktop. The travel industry will never be same again with the advent of mobile technology.

Android technology has a major hold on the market nearly $80 \%$ mobile devices are powered by android.

Android is built on open Linux Kernel. The software developed for Mobile Application is made to be open source. [6] Build on custom virtual machine android gives its users the addition usage and application power, to initiate an interactive and efficient application and operational Software for your phone. Mobility has become everything nowadays; everything has been made easy using mobility.

Now since all the activities of the users are shifted from desktop to mobile devices, there arises the new opportunities to interact with the products from mobile. Therefore, we are providing passengers with an android application, through which passengers can book their ticket using Railway wallet or net-banking. This paper basically describes how the passengers can book the tickets without standing in Queue's. They just have to enter the WIFI zone, use the application provided to book the ticket, thereby completely eliminating the long queues. The database used here is firebase database. Only the registered users will be allowed to book the tickets.

\section{LITERATURE SURVEY}

[1] This paper mainly focuses on reducing the long Queues at ticket counter by using Android application i.e. Android suburban railway(ASR) provided with GPs facility. This GPS facility helps to validate and delete the ticket automatically after a specific interval of time once the user reaches the destination. The ASR ticket can be directly booked through smart phone and can be carried with oneself as a QR (Quick response code). All the user's information is stored in cloud for providing good security in the system. Also, a checker is provided separate checker application to verify the tickets. 
The different technologies used here are: - RFID readers, ARM7 Hardware, UART SQLite, Android cloud to device messaging Communication, LCD Display.

framework (C2DM), QR Code.

The major drawback of this system is the GPS used as it violates the security of users i.e. users can be constantly monitored as he moves. Also, GPS signals are not accurate due to obstacles to the signals like tress, buildings etc. Also, GPS is used on battery operated device, if there is battery failure then it's not possible to keep track of user which leads to complete failure of this system.

[2] This system is based on reducing the queues at the counter, it mainly focuses on usage of wallet for booking the ticket to reduce the network traffic also the user need not to enter payment details every time he wants to book the ticket. It saves time by making complete procedure online. The database used here is SQLite, using this the time required to book ticket is reduced. E-Wallet scheme is recently added to IRCTC website which allows each user to have wallet account also deposit money in advance to their wallet account and use this money to book the ticket.

The different technologies used here are: -

Android, SQLite, Tools also Eclipse and Android SDK are the tools used for developing the java-based applications.

The drawback of the system comes into scenario when user is unaware that there is inefficient balance in wallet and again he has to stand in queue for booking the ticket as there is no alternative solution for booking the ticket.

[3] This paper focuses on automatic ticket vending machine(ATVM) by using RFID and Zigbee techniques. It basically aims at reducing the quarrels and mesh at ticket counters, also replacing the paper ticket with RFID tickets and vouchers. It's completely automated system in which person books the ticket on Automated ticket vending machine(ATVM). The machine is provided with display panel which displays different options like showing destinations, availability of trains, no of tickets, single or return journey etc. The person books the ticket by pressing the button using Zigbee technique. The person then needs to verify himself by showing the ticket at doors of the train. The RFID technique is employed at the doors. When the ticket is shown at the doors, the door opens and again closes back in sometime.

Different hardware and Software technologies used are: -

\section{PROPOSED SYSTEM}

\section{A. Figures}

Figure 1: illustrates a detailed ticket booking system using Wi-Fi zone.

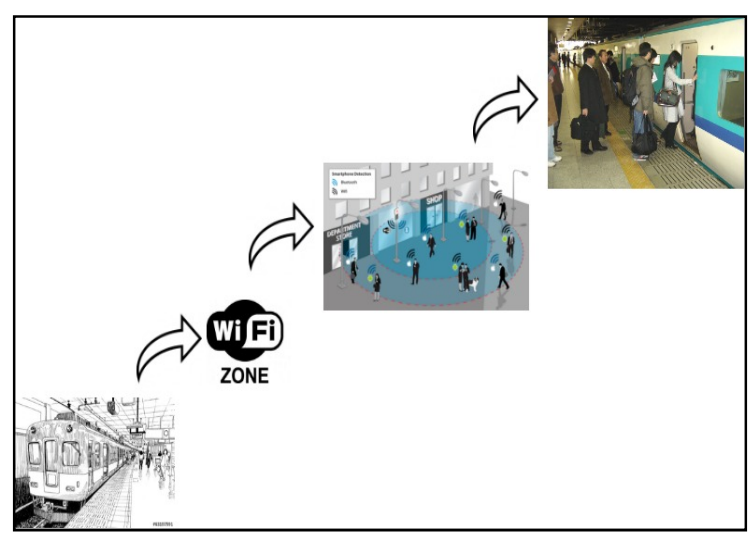

Figure 2: illustrates working of flow of the system.

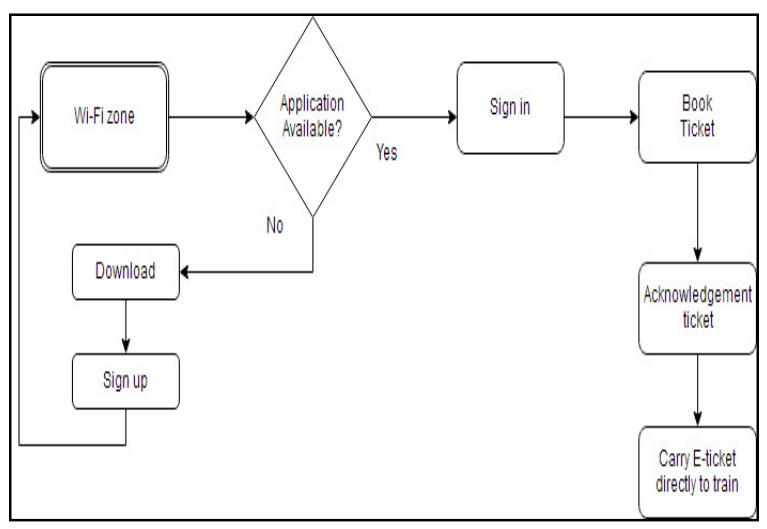

Figure 3: illustrates working of Android application.

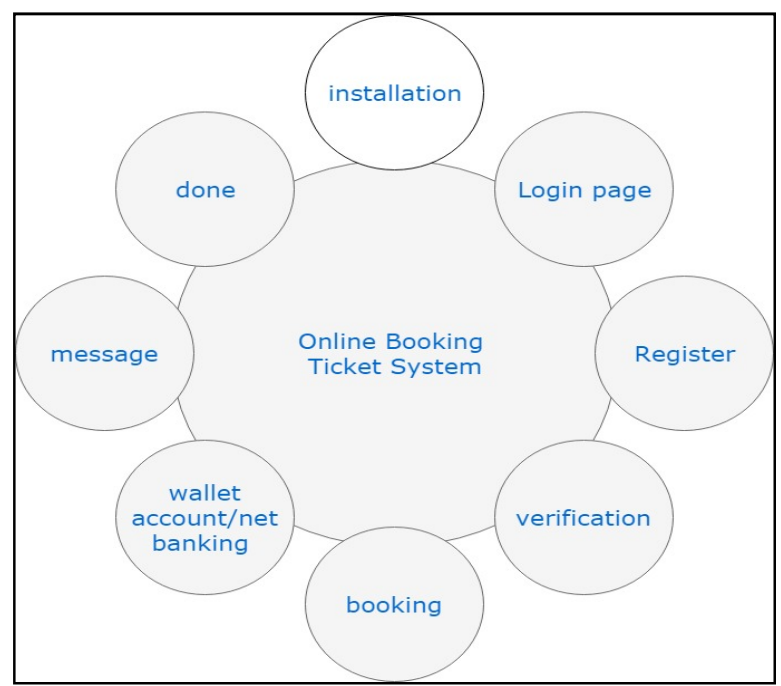




\section{B. Description of System}

The main aim of the proposed system is to reform the current ticket booking process for Suburban Railway. With the help of this application travelers will be able to book the ticket through their mobile using the WIFI connectivity. It can also keep the track of most recent tickets purchases. This is an effort towards queue less ticket booking system and helps passengers utilize their time, which they waste awaiting in the queue. This system provides facility and flexibility to book the ticket using restricted WIFI zones available on platforms. Provided Android application can be only accessed within the WIFI zones only. After ticket booking, tickets will be downloaded directly on smart Phones. Users can directly carry the E-Ticket in the train.

System consists of the following steps: -

1. First the user has to download the provided android application and sign up.

2. Log In page will be provided for passengers and TC (Ticket Checker).

3. Separate login will be provided for TC to verify the tickets of passengers travelling (User just needs to provide a unique no to $\mathrm{TC}$ for Verification).

4. Users can register through phone no, email id, username, city etc. also he has one of the many identity proofs he has.

5. After registering he can book ticket by selecting different options provided like Source, destination, single or return ticket, child or adult, Quantity of tickets etc.

6. Also, the application contains different modules, one of which displays the timetable of the trains available.

7. The other module displays the list of all the recently purchased ticket, thereby helping in keeping the track of recent tickets booked.

8. Now for making the payment two option will be provided i.e. Railway wallet and Internet banking, whenever the passenger of short of money in wallet he can do the payment through internet banking.

9. After the completion of payment, he can book the ticket and the ticket will be sent to him in the form of SMS.

10. The TC (Ticket Checker) has been manually assigned a password using that he can log in the system.
11. The TC is being provided with separate database that contains list of tickets booked within $24 \mathrm{hr}$ period of time.

This system Promotes Paperless and cashless work.

\section{Implementation Details}

Android:

Android is developed by Google, it acts as an open source. [5] It is a mobile operating system. Android which is mobile operating system can be used by several types such as smart phones and tablets. Smart phones can be Samsung s7, Sony Xperia, Nokia etc. Day to day android comes up with new versions for smart phones and tablets and also for different watches. Android programs are written in basically in Java and run through JVM i.e. Java virtual machine which is optimized for mobile devices.

Key features of android are: -

1) It provides flexibility

2) Also provides user friendly environment

3) Memory efficiency

4) Reliable

5) Scalability

6) User can easily communicate

Firebase Database:

The firebase is used as a database in our system as it has many benefits compared to other databases like SQL, SQLite, and Oracle etc. it's used to power the app's backend which includes data storage, user authentication, static hosting and more.

Following are the advantages of firebase: -

1. Firebase offers simple control dashboard.

2. There are number of useful services to choose.

3. It's simple and user friendly. No need for complicated configurations.

4. The data is real-time, which means that any change occurred will automatically update connected clients.

\section{Algorithms used}

AES Algorithm:

This algorithm is used to provide encryption on data stored in firebase database for security purpose. All the data will go in the encrypted format in database so that there is no misuse of important information. It's one of the most powerful algorithm. It's not crack able since the number of combinations of the keys are massive. 
To encrypt sensitive data which is implemented in software and hardware it can be done with the help of AES which is a symmetric block cipher chosen by US government to protect. It can be against brute force attacks.

Key features are as follows:

Cost: This is released under non-exclusive and global, royalty free basis, the algorithm is evaluated on memory efficiency and computation.

Implementation: The algorithm provides flexibility, suitability which should be in implemented in hardware or software, and also provides relatively simplicity in implementation

Security: It provides powerful security. For e.g. if a user wants to send message to a receiver by using AES algorithm it can send message to intended receiver without any intrusion between them. AES is used for encrypting and decrypting big data with more flexibility, efficiency and also more reliable.

$\mathrm{B}+$ tree Algorithm:

This algorithm is used for fast searching of elements, in our system TC needs to check the tickets from the record been provided from database, phone number is chosen as unique element here and $\mathrm{B}+$ tree algorithm is applied for fast searching of the data.

Some of its features are:

- It's used in database.

- Best suited for range queries.

- All the data is stored at leaf node and every leaf is at same level.

- It offers fast record search and traversal.

- All the leaves have pointer to each other.

- Here the threshold is to be provided

$\circ$ Threshold level $(\mathrm{m})=$ maximum number of elements at the node.
VI. Advantages of system

\begin{tabular}{|c|c|c|}
\hline Parameters & Previous system & Our System \\
\hline Queue & Reduced & $\begin{array}{l}\text { Completely } \\
\text { eliminated }\end{array}$ \\
\hline GPS & $\begin{array}{l}\text { Proposed use of } \\
\text { GPS may } \\
\text { violate security } \\
\text { of person }\end{array}$ & $\begin{array}{l}\text { No such use of } \\
\text { GPS. }\end{array}$ \\
\hline Cost & $\begin{array}{l}\text { Cost of ATVM } \\
\text { is high }\end{array}$ & $\begin{array}{lr}\text { WIFI } & \text { Router } \\
\text { used has } & \text { lower } \\
\text { cost } & \text { than } \\
\text { ATVM } & \end{array}$ \\
\hline Paper usage & $\begin{array}{l}\text { Paper used thus } \\
\text { more paper } \\
\text { waste generated. }\end{array}$ & $\begin{array}{l}\text { Complete } \\
\text { paperless work. }\end{array}$ \\
\hline Proof & $\begin{array}{l}\text { Paper ticket } \\
\text { once lost, there } \\
\text { is no proof to be } \\
\text { show to TC }\end{array}$ & $\begin{array}{l}\text { E-ticket } \\
\text { phone can be } \\
\text { shown to TC } \\
\text { and if battery } \\
\text { down or phone } \\
\text { lost TC can } \\
\text { verify from App } \\
\text { provided }\end{array}$ \\
\hline Booking area & $\begin{array}{l}\text { Android } \\
\text { application } \\
\text { supports } \\
\text { booking ticket } \\
\text { from any place. } \\
\text { This lead to } \\
\text { misusage of the } \\
\text { application. }\end{array}$ & $\begin{array}{l}\text { No misuse of } \\
\text { application as } \\
\text { ticket can be } \\
\text { booked only at } \\
\text { stations within } \\
\text { some restricted } \\
\text { area. }\end{array}$ \\
\hline Payment & Wallet system. & $\begin{array}{lr}\text { Wallet } & \text { system } \\
\text { with } & \text { net } \\
\text { banking. } & \\
\end{array}$ \\
\hline $\begin{array}{l}\text { Database or } \\
\text { cloud }\end{array}$ & $\begin{array}{l}\text { SQLite, } \\
\text { MYSQL }\end{array}$ & Firebase used. \\
\hline Smartcard & $\begin{array}{l}\text { Need to be } \\
\text { carried at every } \\
\text { place. }\end{array}$ & No usage. \\
\hline
\end{tabular}

VII. Future scope

- Android application can be provided in different languages to book tickets.

- Application can be extended for issuing the pass.

- This application can be also made available for iOS, blackberry etc. operating system.

- While booking the ticket if a person books the ticket from station $\mathrm{A}$ to $\mathrm{B}$ and travels $\mathrm{A}$ to $\mathrm{C}$ at 
that instances of time the amount will get deducted from his/her account.

- As it's possible to track the location of trains, through this we can also display the platform number on which the train is going to arrive on the android application.

\section{CONCLUSION}

In this paper we have proposed booking of suburban train tickets through android application, which will work within provided WIFI zone using Firebase as a database. The main aim of the system is to completely eliminate the long Queues at ticket counter, thereby providing passengers with flexibility and ease.

\section{References}

1) Karthick. S and Velmurugan. A (2012), "Android Suburban Railway Ticketing with GPS as Ticket Checker" -IEEE International Conference on Advanced communication control and computing Technologies.

2) N.M Girinivas*, P. Hemanand*, K.P. Chetan, S.R. Janani (2015), "Local Train ETicket Reservation system using wallet system" -IJCSMC, Vol. 4, Issue. 3, March 2015, pg.201-207.J. Nagalakshmi, J.V.V. Priya darsini (2014),'RFID based railway ticket booking system with mobile based architecture" -IJAER 2014, Vol No.8, Issue No. III, Sep.

3) Mazhar Abbas, "Challenges in implementation ofTVM (Ticket vending machine) in developing countries for mass transport system: A study of human behavior while Interacting with Ticket vending machine-TVM".

4) Mark Murphy's (2011) "Beginner Android 3" Apress Publications."Androidsystem",

5) http://en.wikipedia.org/wiki/Android(operating system)".

6) Ben Ammar Hatem Hamm Habib, "Bus management system using RFID in WSN", European and Mediterranean conference on Information Systems 2010(EMCIS 2010)April 123 2009, Abu Dhabi, UAE

7) "Local train ticket booking App- new gift from railway toMumbaikars",

8) https://www.services.irctc.co.in/betahtmls/IRCTC andriod App.html
9) Sharmila, A. Ponmalar, Skanda Gurunathan,"Buss pass and ticket automation system",IJCERT Volume 3, Issue 8, August-2016, pp. 389-393. https://firebase.google.com/products 